\title{
NY-ESO-1-specific CD4-positive T Lymphocytes
}

National Cancer Institute

\section{Source}

National Cancer Institute. NY-ESO-1-specific CD4-positive T Lymphocytes. NCI

Thesaurus. Code C117724.

A preparation of autologous CD4+ T-lymphocytes sensitized to cancer-testis antigen NY-ESO-1, with potential immunostimulating and antineoplastic activities. CD4-positive T-lymphocytes are exposed to a NY-ESO-1 peptide ex vivo, expanded, and introduced into the patient. The NY-ESO-1-specific CD4-positive T-lymphocytes may stimulate the host immune system to produce a cytotoxic T-lymphocyte (CTL) response against tumor cells expressing the NY-ESO-1 antigen, which results in tumor cell lysis. NY-ESO-1, an antigen found in normal testis, may be upregulated in various cancers. 